psychiatrists, they assume that their roles and attitudes can be taken for granted. Sadly, this is not the case. There are two small vocal minorities at either extreme, one openly hostile to the claims of psychotherapeutics, the other maintaining that psychotherapy is so undervalued as to have led to an 'imbalance in British psychiatry' (Aveline, 1984). The silent majority appears to occupy a middle ground, understandably bemused by the conflicting views on the professional status as well as the content of psychotherapy. Is it, as some assert, an integral part of medicine or, as a Professions Joint Working Party (Report, 1980) has claimed, is medicine "merely one of the fields adjoining psychotherapy?" Is it a core discipline or, in the words of one professor of psychiatry, is it "more like physiotherapy and social work . . . an adjunct to medical treatment?" (Hirsch, 1984). Or is it a powerful placebo?

Psychotherapy is clearly too large an issue to be left to the psychotherapists. The time would seem to be ripe for a vigorous initiative on the part of the College to help define its nature and role in the light of past experience, present disagreements and future prospects within the National Health Service.

Institute of Psychiatry,

\section{Michael ShePherd}

De Crespigny Park.

Denmark Hill,

London SE5 8AF

\section{References}

Aveline, M. (1984) What price psychiatry without psychotherapy? Lancet, ii, 856-859.

Editorial (anon) (1983) Psychotherapy: effective treatment or expensive placebo? Lancet, i. 83-84.

Frank. J. D. (1983) The placebo is psychotherapy. The Behavioral and Brain Sciences. 6, 291-292.

GWYNNE JoNes, H. (1985) Psychotherapy Research. Journal of the Royal Society of Medicine, 78, 3-6.

HiRsCH, S. (1984) What price psychotherapy? British Medical Journal, (correspondence). 289, 316.

Prioleau, L., Murdock, M. \& Brody, B. (1983) An analysis of psychotherapy versus placebo studies. The Behavioral and Brain Sciences, 6, 275-285.

Rice. L. N. \& Greenberg, L. S. (1984) The New Research Paradigm'. In Patterns of Change (eds. L. N. Rice \& L. S Greenberg). New York: Guildford Press.

ShEPHERD, M. (1984) What price psychotherapy? British Medical Journal, 288, 809-810.

- (1985) Sherlock Holmes and The Case of Dr. Freud. London: Tavistock. (In press).

Steiner, J. (1985) Psychotherapy under attack. The Lancet, $i$, $266-267$.

DeAR SIR,

In their comments on Michael Shepherd's article "What Price Psychotherapy?", Bloch \& Lambert make an astonishing number of factual errors, as well as being highly selective in their references. As an illustration of the first point, they quote Smith $e t$ al (1980), among others, as showing that "the effects of psychodynamic therapy have been compared with the placebo control condition, along similar lines to the Prioleau work. But, and this is a crucial difference, these other reviewers have been far more circumspect and cautious in interpreting their data." (p. 97.) The truth could not be more different. In the first place, as every reader of the Smith et al book, will know, these authors did not compare various therapies with placebo conditions, but with no treatment, and to add insult to injury they used placebo treatment as an example of psychotherapy, to be compared with no treatment! (p. 89). In fact, the average effect size of placebo treatment in their work was 0.56 , that of psychodynamic therapy 0.69 , a quite insignificant difference. Thus one of the main witnesses deduced by Bloch \& Lambert finds pretty much the same results as Prioleau, namely no difference between psychodynamic therapy and placebo treatment.

Are Smith et al "far more circumspect and cautious in interpreting the data"? To my mind, their conclusions are so outrageously exaggerated, and out of line with their data, as to make their whole book a mockery. They conclude, for instance, that "psychotherapy is beneficial, consistently so and in many different ways. Its benefits are on a par with other expensive and ambitious interventions, such as schooling and medicines . . . psychotherapy benefits people of all ages as reliably as schooling educates them, medicine cures them, or business turns a profit". This hymn of joy should be compared with the actuality of their comparison between the effects of dynamic therapy and placebo treatment!

Bloch \& Lambert also fail to mention two other "findings" of the Smith et al meta-analysis which may be relevant. The first of these is that duration of treatment is completely uncorrelated with success of treatment. The second is that length of experience of the psychotherapist is completely uncorrelated with success of treatment. And the third finding, which admittedly Smith et al tried to wriggle out of by means of a very subjective argument, is that behaviour therapy is clearly superior to psychotherapy. If all this is true, then surely the "psychotherapy" they talk about is not the psychotherapy we know and love!

The selectivity of the references cited by Bloch \& Lambert is clearly shown by the fact that they do not mention "the effects of psychological therapy" by Rachman \& Wilson (1980). This book demonstrates in great detail why the conclusions of 
authors who have reviewed the evidence and come to favourable conclusions about the effects of psychotherapy are unacceptable, pointing out the many errors of omission and commission characteristic of this type of work. Bloch \& Lambert are certainly right in saying that "psychotherapy requires an answering commitment to its intelligent and rigorous study, as well as the exploration of new paradigms for research." This aim is hardly furthered by optimistic and unwarranted conclusions about the effectiveness of psychotherapy as it is practiced at the moment, or the failure to look at the facts as they really are. The question I raised 30 years ago (Eysenck, 1952) concerning the effectiveness of psychotherapy cannot be so easily swept under the carpet. The negative conclusion I came to then is still not contradicted by any facts I know of. Only behaviour therapy has succeeded in clearly beating bogey, but traditional psychotherapy has still failed to demonstrate its superiority to placebo treatment, and psychoanalysis in particular has been shown to have frequently very detrimental effects on the mental health of patients (Strupp et $a l, 1977)$. There clearly is very little ground for optimism in all this!

Institute of Psychiatry,

\section{H. J. Eysenck}

De Crespigny Park,

Denmark Hill,

London SE5 8AF

\section{References}

Eysenck, H. J. (1983) Special review of M. L. Smith, G. V. Glass and T. I. Miller: The benefits of psychotherapy. Behaviour Research and Therapy, 21, 315-320.

Rachman, S. J. \& Wilson, G. T. (1980) The Effects of Psychological Therapy. London: Pergamon Press.

SMITH, M. L., Glass, G. V. \& Mil.Ler, T. I. (1980) The Benefits of Psychotherapy. Baltimore: John Hopkins University Press.

Strupp, H. H., Hadley, S. W. \& Gomez-SchwaArtz, G. (1977) Psychotherapy for Better or Worse: The Problem of Negative Effects. New York: Jason Aronson.

\section{Correspondence}

\section{DeAR Sir,}

\section{CIRCADIAN RHYTHMS}

Roy-Byrne et al's paper on 'Approaches to the evaluation and treatment of rapid cycling affective illness' (Journal, November 1984, 145, 543-550) was of great interest in the way it was able to draw together the research findings and weld them into an approach to clinical evaluation of the individual patient. Theoretically this is a very important group of patients and so it was with some concern that I noted an apparent error in the theoretical section of the paper. Tricyclic antidepressant drugs are stated to be similar to oestrogen in their ability to "accelerate the frequency of free running circadian rhythms" (Wirz-Justice et al, 1980). As can be seen from the reference (which is reproduced below) the paper which was quoted, in accordance with most of the other literature, (Thompson, 1984) actually shows a slowing of circadian rhythms under free running conditions. This error rather detracts from the theory, which is suggested later in the paper, that rapid cycling illness is due to an unusually short intrinsic period, or the induction of a short period by tricyclic antidepressants.

In the same issue Drs Nair and Hariharasubramanian (Journal, November 1984, 145, 557) criticise my recent review of circadian rhythms for leaving out studies of the melatonin rhythm in depression. In this context it is necessary to distinguish clearly between a reduction of melatonin secretion (Beck-Friis et al, 1984; Claustrat et al, 1984) which does not necessarily have any implications for an underlying circadian abnormality, and a phase shift in secretion which does. Dr Nair refers to a study which shows the onset of the melatonin rhythm to be delayed in depressed patients (Nair et al, 1984). I look forward to reading the definitive report of this work (at present the reference is to an abstract) and at this time would only comment that the result is contrary to other published data which purport to find a phase advance of melatonin (Lewy, 1983). Our own work (Thompson et al, 1983, 1985) has found no phase shift in depressed patients, either before 